\title{
Rhino-Orbito-Cerebral-Mucormycosis During the COVID-19 Second Wave in 2021 - A Preliminary Report from a Single Hospital
}

\author{
Ritu Arora' \\ Ruchi Goel (D)' \\ Samreen Khanam' \\ Sumit Kumar' \\ Shalin Shah' \\ Sonam Singh' \\ Mohit Chhabra' \\ Ravi Meher ${ }^{2}$ \\ Nita Khurana ${ }^{3}$ \\ Tanu Sagar ${ }^{4}$ \\ Suresh Kumar ${ }^{5}$ \\ Sandeep Garg ${ }^{5}$ \\ Jyoti Kumar ${ }^{6}$ \\ Sonal Saxena ${ }^{4}$ \\ Rashmi Pant ${ }^{7}$ \\ 'Department of Ophthalmology, Guru \\ Nanak Eye Centre, Maulana Azad Medical \\ College, New Delhi, India; ${ }^{2}$ Department \\ of Otorhinolaryngology, Maulana Azad \\ Medical College, New Delhi, India; \\ ${ }^{3}$ Department of Pathology, Maulana Azad \\ Medical College, New Delhi, India; \\ ${ }^{4}$ Department of Microbiology, Maulana \\ Azad Medical College, New Delhi, India; \\ ${ }^{5}$ Department of Medicine, Maulana Azad \\ Medical College and Lok Nayak Hospital, \\ New Delhi, India; ${ }^{6}$ Department of \\ Radiodiagnosis, Maulana Azad Medical \\ College and Lok Nayak Hospital, New \\ Delhi, India; ${ }^{7}$ Society for Health \\ Education and Allied Research, New \\ Delhi, India
}

Correspondence: Ruchi Goel Department of Ophthalmology, Guru Nanak Eye Centre, Maulana Azad Medical College, New Delhi, I 10002, India Tel +9| 98II305645; +9I-II-4I440I08 Email gruchil@rediffmail.com
Purpose: To list the clinico-epidemiological profile and possible risk factors of COVID-19 associated rhino-orbital-cerebral mucormycosis (CA-ROCM) patients presenting to a COVID dedicated hospital during the second wave of COVID-19 in India.

Patients and Methods: A cross-sectional, single-center study was done on 60 cases of probable CA-ROCM based on clinical features and supportive diagnostic nasal endoscopic findings and/or radiologic findings. Patients with recent or active COVID-19 were included. The demographic profile, clinical features, possible risk factors and diagnostic workup (microbiological, pathological and radiological) were analysed to identify the triggering factors for CA-ROCM.

Results: The age of patients ranged from 29 to 75 years and male-female ratio was 3:1. The duration between the first positive COVID report and onset of CA-ROCM was 0 to 47 days. Forty-nine $(81.66 \%)$ patients had a recent COVID infection and $11(18.33 \%)$ had active COVID infection at presentation. Thirty-five patients (58\%) had ocular/orbital involvement at presentation. In the affected eye, 10 had no perception of light and in the rest visual acuity ranged from log MAR 0 to +1.5 . Ocular manifestations were ptosis (29), ophthalmoplegia (23), periocular tenderness and edema (33), proptosis (14), black discoloration of eyelids (3), facial palsy (3), endophthalmitis (4), retinal artery occlusion (8), disc edema (4) and disc pallor (5). Twenty-two (25\%) patients had neither received steroids nor oxygen. Thirty patients $(50 \%)$ were managed with oxygen while 38 patients $(63.3 \%)$ with systemic steroids. The most common risk factor was diabetes in 59 patients. The average glycosylated hemoglobin $(\mathrm{HbA1c})$ was $10.31 \pm 2.59 \%$. Systemic Amphotericin B was started in all the patients. Radical surgical debridement was performed in 12 patients and the remaining were planned.

Conclusion: SARS-CoV-2 variant with accompanying glycaemic dysregulation was found to be the triggering factor for the epidemic of CA-ROCM.

Keywords: COVID-19 treatment, CA-ROCM, orbital apex syndrome, ophthalmoplegia, retinal arterial occlusion, COVID-19 associated rhino-orbital-cerebral mucormycosis

\section{Introduction}

India's resurgence in COVID infections began around mid-March 2021 and increased rapidly, reaching a peak of more than 414,000 daily cases on May 6,2021. The daily death toll rose to 3754 by May 9, 2021. ${ }^{1}$ While the onslaught continued, another invisible foe entered the arena in the form of COVID-19 associated Mucormycosis (CA-ROCM). CA-ROCM had been recognized during the first wave in India. By June 7, 2021, a deluge of 28,252 
Mucormycosis cases was reported, $86 \%$ having history of COVID-19. Interestingly, the Indian SARS CoV-2 genomic consortium found the delta variant (B.1.617.2) to be responsible for $>90 \%$ COVID cases in May 2021 in comparison to $<5 \%$ before January $2021 .{ }^{3}$

CA- ROCM has a world-wide distribution, the major chunk being contributed by India. In a systematic review of 101 cases of mucormycosis with COVID-19, 82 were from India and the remaining 19 from USA (9), Iran (3), UK (1), France (1), Italy (1), Brazil (1), Turkey (1), Mexico (1) and Austria (1). ${ }^{4}$ Recently, 15 more cases from 5 centers in Iran from April to September 2020 and 2826 cases from 98 centers between January 1, 2020 and May 26, 2021 in India have been reported, reflecting the magnitude of the disease burden. ${ }^{5,6}$ Most of the reports of ROCM include the time period over 2020 till May 2021. There exists only one report of 70 cases of ROCM exclusively in the severe, devastating second wave of COVID 19 starting in April 2021. ${ }^{7}$

A preliminary study was thus designed to document the clinical along with microbiological, pathological, radiological features and possible risks to gain an insight into the triggering factors for the swarm of COVID-19 associated ROCM and to formulate guidelines for prevention of the disease.

\section{Materials and Methods}

A cross-sectional study was conducted on CA-ROCM patients, admitted in the single largest COVID dedicated hospital in India. After obtaining institutional ethical committee clearance (F.1/IEC/MAMC/(84/02/2021/No.396), the hospital patient data repository was screened for patient files with diagnosis of probable ROCM and COVID-19 between May 15 and June 5, 2021. Written informed consent was taken and probable ROCM patients with documented COVID-19 infection from March 2021 onwards were included in the study. The study complies with the Declaration of Helsinki and all organs were donated voluntarily with written informed consent, in accordance with Declaration of Istanbul. A patient with clinical features suggestive of ROCM, supported by nasal endoscopy findings or imaging was diagnosed as probable ROCM. Patients with incomplete records or those, unable to give consent were excluded from the study. A detailed data collection sheet was formulated for the information to be collected from the hospital records based on demographic profile, vaccination status, date of COVID-19 diagnosis, date of onset of CA-ROCM symptoms, clinical features of ROCM, associated co-morbidities, glycosylated hemoglobin (HbAlc) status, treatment received for COVID-19, nasal endoscopy findings, microbiological, pathological and radiological details, medical treatment initiated for ROCM, surgical planning and/or execution.

Details of recent COVID-19 presentation and severity were retrieved from the available documents with the patients. ROCM was staged as per the proposed code mucor guidelines for staging. ${ }^{8}$ The diagnosis of COVID19 was based on documented positive reverse transcriptase polymerase chain reaction (RT-PCR) or rapid antigen report of naso-oropharyngeal swab. Patients recovered from COVID-19 infection three months prior and currently RT-PCR negative for SARS-CoV2 were designated as recent COVID-19. The time limit of three months was taken as per the widely accepted definition of post-acute COVID-19 syndrome. ${ }^{9}$ Active COVID-19 cases were defined as patients who were laboratory confirmed for SARS-CoV-2 (by rapid antigen or RT-PCR) at presentation. The severity of COVID-19 was based on the prescribed Indian government guidelines. ${ }^{10}$ Mild COVID-19 cases were to be managed in home isolation with symptomatic treatment and oral Ivermectin $(200 \mathrm{mcg} / \mathrm{kg}$ once a day for 3-5 days). Patients with moderate to severe disease were hospitalized. They were managed with oxygen therapy, anticoagulation, awake proning, intravenous (IV) methylprednisolone 0.5 to $1 \mathrm{mg} / \mathrm{kg}$ or IV Dexamethasone 0.1 to $0.2 \mathrm{mg} / \mathrm{kg}$ (moderate COVID) and IV methylprednisolone 1 to $2 \mathrm{mg} / \mathrm{kg}$ in two divided doses or IV Dexamethasone 0.2 to $0.4 \mathrm{mg} / \mathrm{kg}$ (severe COVID) usually for a duration of 5 to 10 days. The duration of administration of steroids was to be reviewed and modified as per the clinical response. They were to be initiated or switched to oral route if stable and/or improving. Antibiotics were prescribed only on suspicion of bacterial infection. ${ }^{10}$

\section{Statistical Analysis}

Baseline characteristics of the patients were described using frequencies and percentages for the categorical variables and median and interquartile range for the continuous variables such as age, duration of diabetes, value of $\mathrm{HbAlc}$ and the lag between laboratory confirmation of COVID-19 and detection of ROCM. Duration from laboratory confirmation of COVID-19 and detection of ROCM was dichotomized at the median value as early and late detection of ROCM. Its relationship was explored with potential risk factors such as severity of COVID-19, 
Table I Demographic Profile and Risk Factors for ROCM

\begin{tabular}{|c|c|c|}
\hline Risk Factor & $\begin{array}{c}\text { Number of } \\
\text { Cases/Median }\end{array}$ & $\begin{array}{c}\text { Percentage/ } \\
\text { Interquartile Range }\end{array}$ \\
\hline Age (years) & 57 & $51.5-62$ \\
\hline \multicolumn{3}{|l|}{ Gender } \\
\hline Male & 45 & 75 \\
\hline Female & 15 & 25 \\
\hline \multicolumn{3}{|c|}{ COVID Vaccination status } \\
\hline No dose & 53 & 88.3 \\
\hline First dose & 7 & 11.7 \\
\hline \multicolumn{3}{|c|}{ Severity of COVID infection } \\
\hline Mild & 26 & 45.6 \\
\hline Moderate & 28 & 49.1 \\
\hline Severe & 3 & 5.3 \\
\hline \multicolumn{3}{|l|}{ Oxygen } \\
\hline Not given & 30 & 50 \\
\hline Given & 30 & 50 \\
\hline \multicolumn{3}{|c|}{ Place of receiving treatment } \\
\hline Home quarantine & 22 & 36.6 \\
\hline Health facility & 38 & 63.3 \\
\hline \multicolumn{3}{|c|}{ Steroid administration } \\
\hline None & 22 & 36.7 \\
\hline Oral & 11 & 18.3 \\
\hline Intravenous & 27 & 45 \\
\hline $\begin{array}{l}\text { Tocilizumab } \\
\text { administration }\end{array}$ & 2 & 3.3 \\
\hline $\begin{array}{l}\text { Diabetes } \\
\text { Mellitus }\end{array}$ & 59 & 98.3 \\
\hline Newly diagnosed & 10 & 16.6 \\
\hline Known diabetics & 49 & 81.6 \\
\hline Diabetic & 3 & 5 \\
\hline ketoacidosis & & \\
\hline $\begin{array}{l}\text { Duration of } \\
\text { diabetes (years) }\end{array}$ & 5 & $2.5-7$ \\
\hline $\mathrm{HbAlc}$ & 9.25 & $8.3-12.6$ \\
\hline \multicolumn{3}{|c|}{ Other Co-morbid conditions } \\
\hline Hypertension & 14 & 23.3 \\
\hline $\begin{array}{l}\text { Coronary artery } \\
\text { disease }\end{array}$ & 6 & 10 \\
\hline $\begin{array}{l}\text { Thyroid } \\
\text { dysfunction }\end{array}$ & 4 & 6.6 \\
\hline $\begin{array}{l}\text { Chronic kidney } \\
\text { disease }\end{array}$ & 2 & 3.3 \\
\hline Stroke & I & 1.67 \\
\hline
\end{tabular}

(Continued)
Table I (Continued).

\begin{tabular}{|l|c|c|}
\hline Risk Factor & $\begin{array}{c}\text { Number of } \\
\text { Cases/Median }\end{array}$ & $\begin{array}{c}\text { Percentage/ } \\
\text { Interquartile Range }\end{array}$ \\
\hline Benign prostatic & $\mathrm{I}$ & $\mathrm{I} .67$ \\
hyperplasia & $\mathrm{I}$ & $\mathrm{I} .67$ \\
Chronic bronchitis & $\mathrm{I}$ & $\mathrm{I} .67$ \\
Carcinoma breast & $\mathrm{I}$ & $\mathrm{I} .67$ \\
On long term & & \\
steroids & \\
\hline
\end{tabular}

presence of diabetes, vaccination status, systemic steroid use, oxygen administration and presenting clinical features using logistic regression model. The regression (effect) estimates were reported as risk ratios (RR) and 95\% confidence intervals. RR was converted to percentages to report increase or decrease in risk of early onset for each of the independent variables mentioned above. The percentage change in risk was calculated as (estimated RR-1) $\times 100$ if $R R>1$ and (1-estimated RR) $\times 100$ if $R R<1$. Since sample size for regression was small, $\mathrm{p}$-values $\leq 0.1$ were considered significant.

\section{Results}

Out of the 65 cases of CA-ROCM admitted during the study period, five were excluded owing to incomplete data. The demographic profile and risk factors for ROCM are given in Table 1. The median age was 57 years, ranging from 29 to 75 years, with male-female ratio being 3:1. Eleven patients had active COVID-19 and 49 were recent COVID-19 cases. None of the cases had received both the doses of COVID-19 vaccine (Covaxin, Bharat Biotech/ Covishield, AstraZeneca, Serum institute of India).

Thirty-eight patients were hospitalized for COVID management earlier and three of them were treated in intensive care units (ICU). Twenty-two patients were treated in home isolation and had not received steroids or oxygen. Corticosteroids were administered in 38 cases, oral (prednisolone/methylprednisolone) in 11 and parenteral (methylprednisolone/ dexamethasone) in 27. The cumulative prednisolone-equivalent dose ranged from $5.7 \mathrm{mg} /$ day to $128.7 \mathrm{mg} /$ day and the total dose being $>600 \mathrm{mg}$ in only 6 patients. Thirty patients had received oxygen for an average duration of $10.8 \pm 3.58$ days. Preexisting diabetes was found in 49 cases, duration ranging from 1 to 25 years, and newly diagnosed diabetes was observed in 10 cases. The average HbAlc levels were 
Table 2 Staging and Clinical Features of ROCM Patients

\begin{tabular}{|c|c|c|}
\hline & $\begin{array}{c}\text { Number of } \\
\text { Cases }\end{array}$ & $\begin{array}{c}\text { Percentage of Cases } \\
\text { (Out of 60) }\end{array}$ \\
\hline \multicolumn{3}{|c|}{ ROCM staging } \\
\hline I & 0 & 0 \\
\hline 2 & 25 & 41.7 \\
\hline 3 & 29 & 48.3 \\
\hline 4 & 6 & 10 \\
\hline
\end{tabular}

First symptom of ROCM

\begin{tabular}{|l|c|c|}
\hline Facial pain & 35 & 58.3 \\
Facial swelling & 12 & 20 \\
Decreased vision & 4 & 6 \\
Black/blood-stained nasal & 3 & 5 \\
discharge & 2 & \\
Diplopia & 1 & 3.3 \\
Headache & 1 & 1.67 \\
Dental pain & 1 & 1.67 \\
Facial numbness & 1 & 1.67 \\
Nasal blockage & 1 & 1.67 \\
Ptosis & 1.67 \\
\hline Laterality of ocular disease at presentation \\
\hline Left & II & 18.3 \\
Right & 24 & 40 \\
\hline
\end{tabular}

Visual acuity in the affected eye at presentation

\begin{tabular}{|l|l|l|}
\hline Log Mar 0 to +1.5 & 50 & 83.3 \\
Loss of light perception & 10 & 16.7 \\
\hline
\end{tabular}

Ocular signs and symptoms related to Mucormycosis at presentation

\begin{tabular}{|l|c|c|}
\hline Total cases & 35 & 58.3 \\
Ptosis & 29 & 48.3 \\
Total ophthalmoplegia & 18 & 30 \\
Periocular tenderness & 17 & 28.3 \\
Periocular edema & 16 & 26.6 \\
Proptosis & 14 & 23.3 \\
Diminution of vision & 12 & 20 \\
Complete loss of vision & 10 & 16.6 \\
Central/branch retinal & 8 & 13.3 \\
artery occlusion & & \\
Partial ophthalmoplegia & 5 & 8 \\
Disc pallor & 5 & 8 \\
Disc edema & 4 & 6 \\
Endophthalmitis with & 4 & 6 \\
severe hypotony & 3 & 5 \\
Black discoloration of & & \\
eyelids & 3 & 3.3 \\
Facial palsy & 2 & \\
Diplopia & \\
\hline Nasal signs and symptoms at presentation & \\
\hline
\end{tabular}

(Continued)
Table 2 (Continued).

\begin{tabular}{|l|c|c|}
\hline & $\begin{array}{c}\text { Number of } \\
\text { Cases }\end{array}$ & $\begin{array}{c}\text { Percentage of Cases } \\
\text { (Out of 60) }\end{array}$ \\
\hline Total cases & 49 & 81.7 \\
Crusting & 36 & 60 \\
Epistaxis & 18 & 30 \\
Nasal blockage & 17 & 28.3 \\
Black discharge & 12 & 20 \\
Nasal ulcer/eschar & 1 & 1.67 \\
\hline
\end{tabular}

Facial signs and symptoms at presentation

\begin{tabular}{|l|c|c|}
\hline Total cases & 39 & 65 \\
Facial pain & 35 & 58.3 \\
Infra-orbital anaesthesia & 27 & 45 \\
Facial swelling & 17 & 28.3 \\
Supra-orbital & 4 & 6 \\
hypoesthesia & \\
Facial discoloration & 3 & 5 \\
\hline Involvement of oral cavity at presentation \\
\hline Total cases & 3 & 5 \\
Dental pain & 2 & 3 \\
Palate perforation & 1 & 1.67 \\
\hline Central nervous system signs and symptoms at presentation \\
\hline Total cases & 6 & 10 \\
Altered sensorium & 3 & 5 \\
Hemiplegia & 2 & 3 \\
Headache & 1 & 1.67 \\
\hline
\end{tabular}

$10.31 \pm 2.59 \%$ (ranging from 6.1 to $14.6 \%$ ) and $>8 \%$ in $88.1 \%$ of the diabetic patients. The lone non diabetic patient had undergone liver transplantation and was on cumulative prednisolone equivalent dose of $15 \mathrm{mg} /$ day, oral mycophenolate mofetil $500 \mathrm{mg}$ twice a day and oral Tacrolimus $1 \mathrm{mg}$ twice a day. Besides diabetes, hypertension was the second most common co-morbidity.

Staging of ROCM patients and their clinical features are presented in Table 2. Facial pain was the commonest first symptom of ROCM patients. Thirty-five of the 60 patients (58\%) belonged to Stage 3 and 4 and had unilateral orbital involvement, ptosis being the commonest ocular manifestation (Figure 1).

The median duration between the first laboratory confirmation of COVID-19 and detection of CA-ROCM was 17 days, ranging from 0 to 47 days, cases detected prior to 17 days were labeled as detected early and the remaining as late. Detection of ROCM was delayed by an average of 7 days (95\% CI: $-13.51,-0.54)$ in patients vaccinated with 


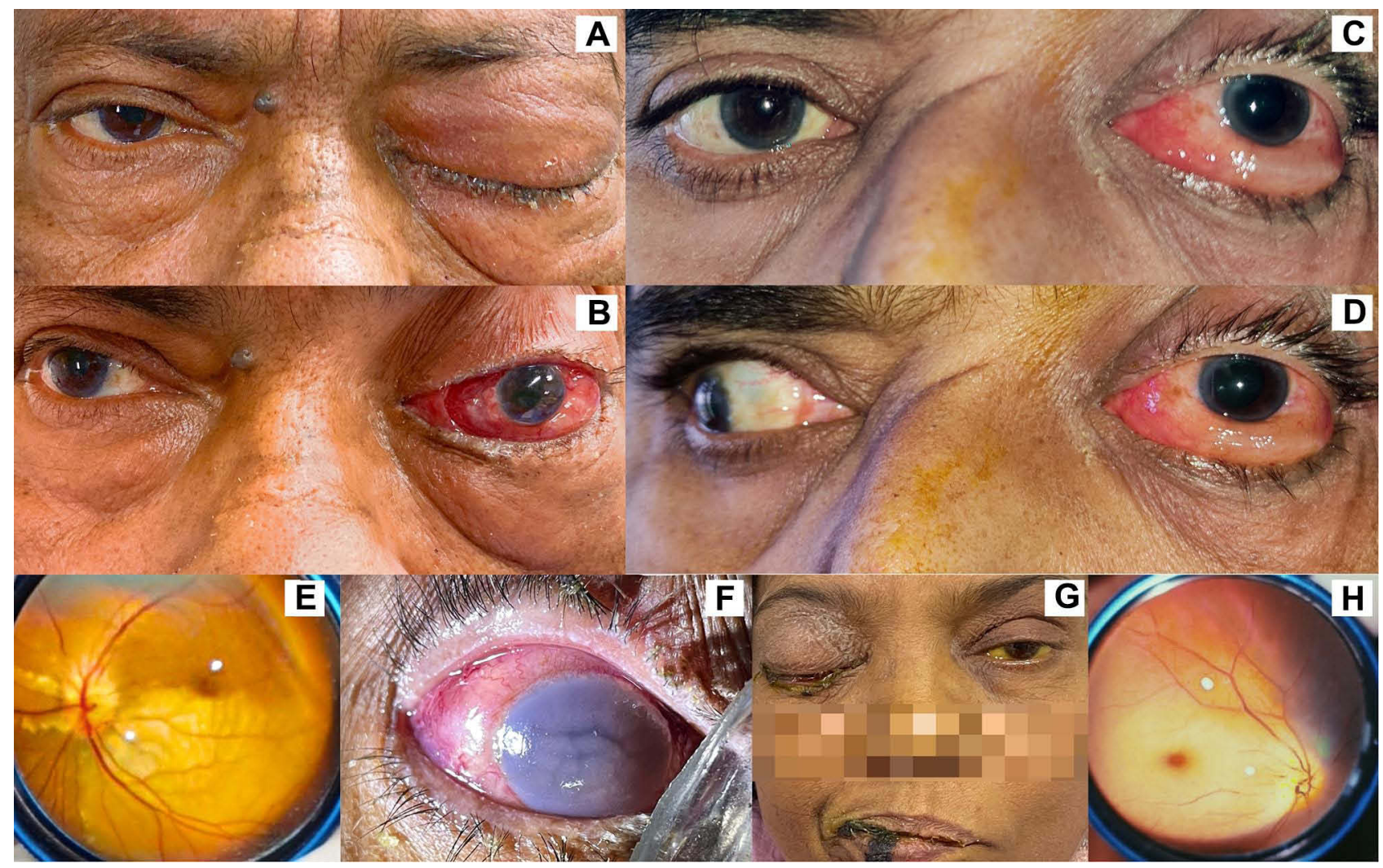

Figure I Clinical manifestations of patients with COVID-I9 associated mucormycosis. (A and B) Left eye showing proptosis and total ophthalmoplegia. (C and D) Left eye showing marked chemosis and total ophthalmoplegia. (E) Bedside fundus image showing right branch retinal artery occlusion. (F) Right-eye endophthalmitis with hypotony and corneal edema. (G) Post liver transplant patient showing right total ophthalmoplegia, icterus and black discoloration of lower lid and lip. (H) Fundus image suggestive of left central retinal artery occlusion.

first COVID-19 dose as compared to those who were not vaccinated $(\mathrm{p}=0.03)$ and an average of 5 days $(95 \% \mathrm{CI}$ : $-9.09,-0.84)$ in those who had been administered oxygen during COVID-19 treatment as compared to those who had not been given the oxygen $(\mathrm{p}=0.02)$. Early detection by 4.7 days $(95 \% \mathrm{CI}: 0.35,9.08)(\mathrm{p}=0.03)$ was observed in cases having facial signs and symptoms on presentation. Presence of any ocular sign/symptom, ptosis and complete loss of vision were also associated with early detection by 2.7 days (95\% CI:-1.61,7.06) $(\mathrm{p}=0.2), 2.26$ days $(95 \% \mathrm{CI}$ $2.03,6.55) \quad(\mathrm{p}=0.3)$ and 2.5 days (95\% CI:-3.19,8.35) $(\mathrm{p}=0.37)$ respectively, though statistically insignificant.

The chances of early detection of ROCM decreased by $35 \%(\mathrm{p}=0.1)$ in moderate COVID-19 infection (Table 3). Higher chance of early detection by $64 \%(p=0.06)$ in patients presenting with ocular sign or symptom and by $42 \%(\mathrm{p}=0.1)$ in patients who had not received systemic steroids was observed.

Initial radiological work up comprised of contrast enhanced computerized tomography (CECT). Magnetic resonance imaging (MRI) was performed in suspected orbital apex lesion or intracranial spread. Thirty-five patients had undergone imaging and the remaining were scheduled in the next few days. Patchy enhancement of the orbital fat (30/35), orbital apex lesion (10/35), thickening of extraocular muscles (14/35), intraocular exudation (4/35) and subperiosteal abscess (2/35) were observed in the orbital scans (Figure 2). Of the 6 patients in stage 4, 3 had focal cavernous sinus involvement and additionally 3 had diffuse cavernous sinus thrombosis with brain infarction at varying sites.

Direct microscopy of the diagnostic nasal endoscopy swab of the 60 cases, using $\mathrm{KOH}$ mount showed non/pauci septate, irregular, broad, ribbon-like hyphae with wide angle non-dichotomous branching in 19 cases, 8 of which grew Mucorales and in 2, both Aspergillus species and Mucorales were isolated on culture (Figure 3). Histopathology of 37 cases was available. Tissue invasion of hyphae consistent morphologically with Mucor were seen in 22, 3 being mixed infection with Candida (1) and Aspergillus species (2). There was presence of acute suppurative cellular reaction (2), necrosis with no cellular reaction (16) and granulomatous reaction in 4 samples. 
Table 3 Association Between Early Detection of ROCM with Various Risk Factors

\begin{tabular}{|c|c|c|c|}
\hline Risk Factor & $\begin{array}{l}\text { Relative } \\
\text { Risk }\end{array}$ & $95 \% \mathrm{Cl}$ & p-value \\
\hline Age (years) & 0.99 & $(0.98,1.02)$ & 0.92 \\
\hline \multicolumn{4}{|l|}{ Gender } \\
\hline Male (Reference) & 1 & & \\
\hline Female & 0.96 & $(0.56,1.65)$ & 0.88 \\
\hline \multicolumn{4}{|c|}{ COVID Vaccination status } \\
\hline No dose (Reference) & I & & \\
\hline First dose & 0.24 & $(0.04,1.47)$ & 0.1 \\
\hline \multicolumn{4}{|c|}{ Severity of COVID infection } \\
\hline Mild (Reference) & I & & \\
\hline Moderate & 0.65 & $(0.3932,1.0927)$ & 0.11 \\
\hline Severe & 0.51 & $(0.1004,2.5879)$ & 0.42 \\
\hline \multicolumn{4}{|l|}{ Oxygen given } \\
\hline Not given & 1.54 & $(0.9509,2.4890)$ & 0.07 \\
\hline Given (Reference) & 1 & & \\
\hline \multicolumn{4}{|l|}{ Place of treatment } \\
\hline Home quarantine & 1.23 & $(0.7822,1.9439)$ & 0.37 \\
\hline Health facility & I & & \\
\hline (Reference) & & & \\
\hline \multicolumn{4}{|l|}{ Systemic steroids } \\
\hline Taken (Reference) & I & & \\
\hline Not taken & 1.42 & $(0.93,2.24)$ & 0.1 \\
\hline \multicolumn{4}{|c|}{ Duration of Diabetes (years) } \\
\hline$<5$ (Reference) & I & & \\
\hline$\geq 5$ & 1.03 & $(0.650 \mathrm{I}, \mathrm{I} .6369)$ & 0.90 \\
\hline \multicolumn{4}{|c|}{ Laterality of ocular disease } \\
\hline None (Reference) & 1 & & \\
\hline Left & 0.8920 & $(0.6148,1.2943)$ & 0.55 \\
\hline Right & $1.106 \mathrm{I}$ & $(0.8259,1.48 \mid 3)$ & 0.50 \\
\hline \multicolumn{4}{|l|}{ Visual acuity } \\
\hline Log MAR 0 to +1.5 & 1 & & \\
\hline Loss of vision & 1.35 & $(0.8285,2.187 I)$ & 0.23 \\
\hline \multicolumn{4}{|l|}{ Ocular symptoms } \\
\hline No (Reference) & I & & \\
\hline Yes & 1.64 & $(0.9608,2.809 I)$ & 0.06 \\
\hline \multicolumn{4}{|l|}{ Ophthalmoplegia } \\
\hline No (Reference) & I & & \\
\hline Yes & 1.25 & $(0.7968,1.9609)$ & 0.33 \\
\hline
\end{tabular}

(Continued)
Table 3 (Continued)

\begin{tabular}{|l|l|l|l|}
\hline Risk Factor & $\begin{array}{l}\text { Relative } \\
\text { Risk }\end{array}$ & $95 \%$ Cl & p-value \\
\hline Proptosis & \multicolumn{1}{|l|}{} \\
\hline $\begin{array}{l}\text { No (Reference) } \\
\text { Yes }\end{array}$ & 0.88 & $(0.4943,1.5830)$ & 0.68 \\
\hline Ptosis & 1 & $(0.8084,2.0354)$ & 0.29 \\
\hline $\begin{array}{l}\text { No (Reference) } \\
\text { Yes }\end{array}$ & 1.28 &
\end{tabular}

All the patients were treated with IV amphotericin B liposomal (Amphonex-Bharat serums and vaccines Ltd.) (IV $5 \mathrm{mg} / \mathrm{kg}$ daily). Functional endoscopic sinus surgery (FESS) was performed in 10 patients. In 2 cases FESS was combined with maxillectomy and orbital exenteration. Transcutaneous retrobulbar amphotericin B injection (Amphomul-Bharat serums and vaccines Ltd.) $(1 \mathrm{~mL}$ of $3.5 \mathrm{mg} / \mathrm{mL})$ daily for 3 days was given in 6 eyes with stage 3 ROCM with diffuse or apical enhancement on contrast enhanced MRI. The remaining 48 patients were planned for radical sinus debridement.

\section{Discussion}

Mucormycosis, is known to be associated with malignant hematological disease, severe neutropenia, uncontrolled diabetes mellitus, iron overload, major trauma, prolonged use of corticosteroids and IV drug abuse. ${ }^{10}$ ROCM, a spectrum of limited sino-nasal, rhino-orbital and rhinoorbital-cerebral disease, often has underlying uncontrolled diabetes and diabetic ketoacidosis (DKA). ${ }^{4,11}$ Of late, increasing numbers of CA-ROCM have been encountered. The vulnerability of COVID-19 patients to mucormycosis has been attributed to presence of diabetes, use of immunosuppressive therapy in moderate to severe cases, ICU stay and mechanical ventilation. ${ }^{8,13,14}$

The median age of affliction of CA-ROCM patients has been reported as $44.5,51.9,52$ and 55 years with male predilection of $60 \%, 71 \%, 66 \%$ and $79 \%$ respectively. ${ }^{5-7,15}$ The demographic profile in our series was similar to previous reports, the median age being 57 with $75 \%$ male preponderance. Factors cited for the skewed male:female ratio are greater exposure to fungal spores due to prolonged out door exposure in males and protective role of oestrogens in females. ${ }^{6,16}$ 


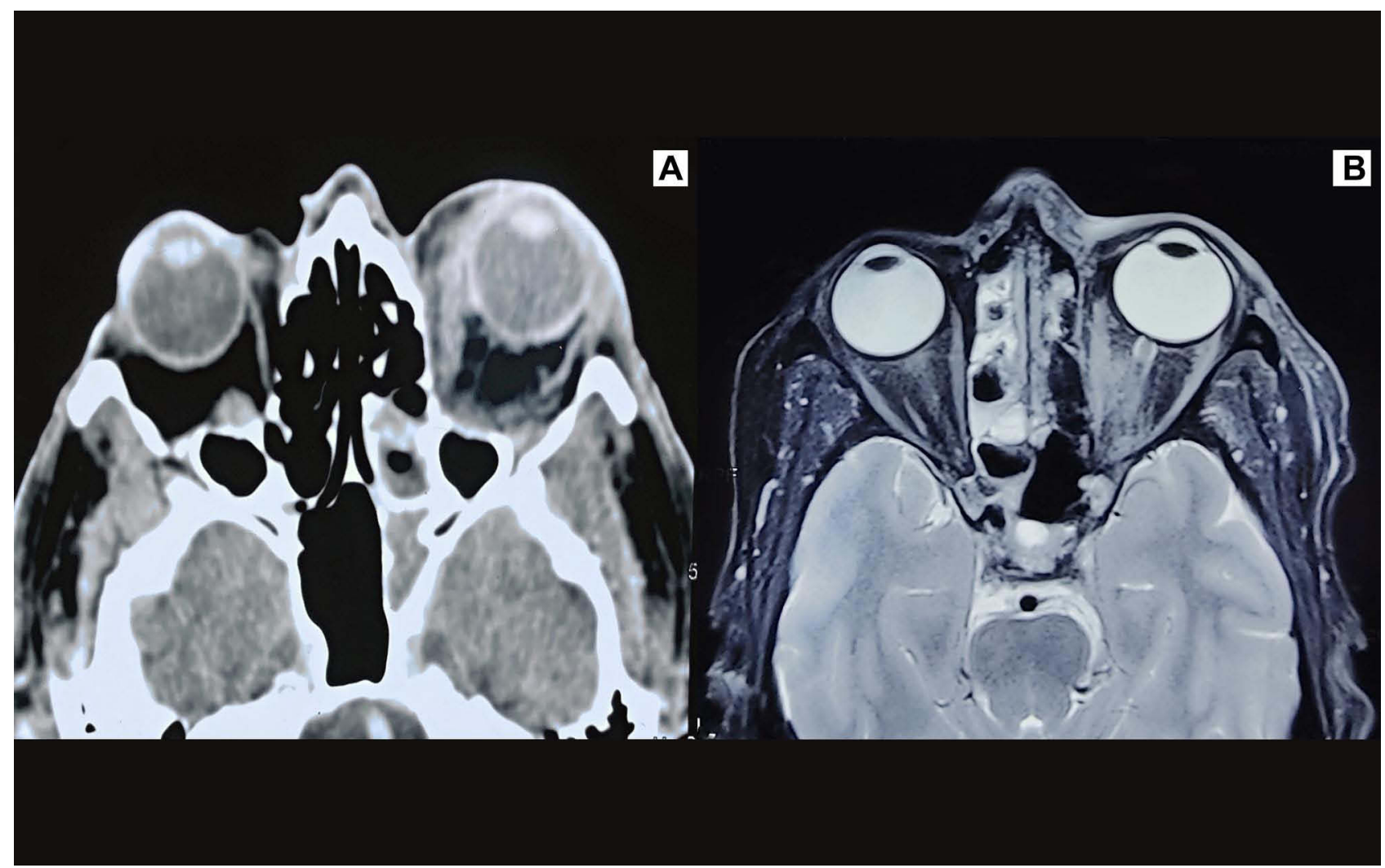

Figure 2 Radiological findings in patients of COVID-19 associated mucormycosis. (A) Axial scan of non-contrast CT of orbit showing left posterior ethmoidal mucosal thickening, proptosis, thickened extraocular muscles with ill-defined hyperdense heterogeneous opacity at the orbital apex and fat stranding in the extraconal and intraconal compartments and infratemporal fossa. (B) Axial scan of T2 -weighted fat suppressed MRI orbit showing residual disease post ethmoidal debridement with bilateral ethmoidal sinusitis, thickening of medial and lateral recti, fat stranding in the intraconal and extraconal compartments and the orbital apex.

In our study, all except one patient were diabetic, $88.1 \%$ having $\mathrm{HbA} 1 \mathrm{c}>8 \%$. Three of these patients suffered from DKA. In 31 cases of ROCM, reported during the first wave in India over 6 months, 30 had uncontrolled diabetes, 6 were newly diagnosed and average value of $\mathrm{HbAlc}$ was $7.57 \% .{ }^{17}$ In a multicentric Indian study comprising of 2826 CA-ROCM patients from both waves, 2194 cases were diabetic, 972 being either uncontrolled diabetes or DKA. ${ }^{6}$ In another retrospective Indian study on CA-ROCM exclusively during the second wave, from April 1, 2021 to June 1, 2021, out of the 70 cases, 49 cases were diabetic, 5 were recently diagnosed and 9 had concomitant DKA. ${ }^{7}$ Poor glycaemic control possibly resulted from cytokine storm and direct injury to the pancreatic beta cells in the backdrop of limited access to routine diabetes care because of lockdown. ${ }^{18}$

Systemic corticosteroids are recommended in moderate and severe COVID-19 cases. $^{10}$ Similar to observation by Ramaswami et al regarding indiscriminate use of steroids, ${ }^{7}$ 4 mild COVID-19 cases in our series, had been prescribed systemic steroids. Cumulative doses $>600 \mathrm{mg}$ for prednisolone and 2-7 g of methylprednisolone predispose immunocompromised patients to mucormycosis. ${ }^{19}$ Though $63.3 \%$ of our patients had history of steroid administration, only six patients had received $>600 \mathrm{mg}$ systemic prednisolone equivalent dose. Twenty-two cases, however, never received steroids but were diabetic. Thus steroids solely may not have contributed to the causation of ROCM. Further, Tocilizumab was administered in only two patients and had an unlikely role to play.

A large numbers of ROCM cases presenting over a short period of time during the second wave, ${ }^{7}$ similar to our study, indirectly points towards causal role of the new viral variant in ROCM. SARS-CoV-2 causes marked reduction in $\mathrm{CD} 4+$ and $\mathrm{CD} 8+\mathrm{T}$-cells, lowering the defence against invasive fungal infections. ${ }^{20}$

Airway epithelial damage in COVID-19 due to oxygen delivery devices, prolonged use of humidifiers without cleaning, use of industrial oxygen, multiple swab tests and steam inhalation burn injuries have been postulated to provide opportunity for fungus to invade lung tissues. ${ }^{21-23}$ 


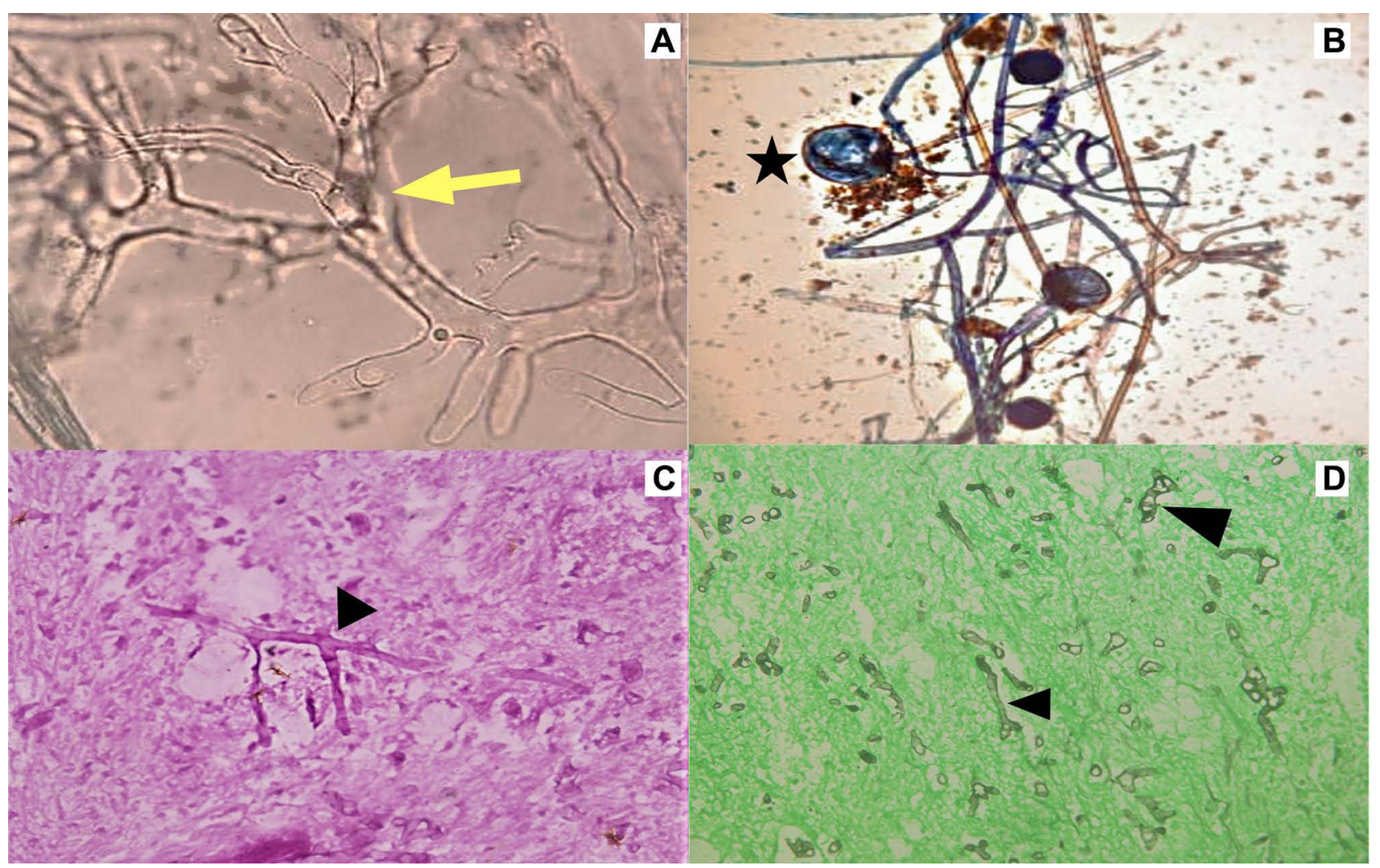

Figure 3 Microbiological and histopathological features of mucorales. (A) $\mathrm{KOH}$ mount showing broad aseptate hyphae (yellow arrow). (B) Lactophenol cotton blue mount showing aseptate hyphae with extension of columella into sporangium (star). (C) Periodic acid Schiff stain (400x) showing broad aseptate hyphae with right angle branching (black arrowhead). (D) Silver methenamine stain (400x) showing broad aseptate hyphae (black arrowhead) in necrotic tissue.

Contaminated oxygen as a possible source of infection was ruled out by Sen et al with $43 \%$ (1216 of 2818 ) of their CAROCM cases never being on oxygen support. ${ }^{6}$ In concurrence, in our series, only 50\% (30/30) had received oxygen support and of the 3 cases treated in ICU, none had been on mechanical ventilation.

Ptosis was the commonest ocular manifestation, present in 29 of the 35 patients. Seven eyes having orbital apex syndrome with central retinal artery occlusion and 3 eyes with endophthalmitis had no light perception. Twelve eyes had diminution of vision due to branch retinal artery occlusion (1), exposure keratitis following facial palsy (3), endophthalmitis (1), optic atrophy (5) and immature senile cataract (2). Though ophthalmoplegia was seen in 23 eyes, only 2 patients complained of diplopia, the remaining 21 having ptosis or poor vision in the affected eye.

Lag between COVID-19 diagnosis and ROCM is reported to vary from 0 to 60 days, consistent with our findings. ${ }^{13,17}$ Detection of ROCM before 17 days (median value in our study) was seen in patients who had not received even a single dose of COVID-19 vaccine, had moderate COVID, had not been administered systemic steroids and had developed ocular or facial signs/ symptoms. Ocular involvement especially vision loss or ptosis and facial signs is likely to alert the patient and physician earlier, leading to earlier detection of ROCM. The protection offered by the single dose of COVID-19 vaccination against ROCM is worth exploring as none of our patients had been fully immunized. In another report of 47 cases of ROCM from January 2 to March 27, 2021, $66 \%(31 / 47)$ had not been vaccinated. ${ }^{24}$

However, no definite explanation could be given for the causal relationship between early detection of ROCM, severity of COVID and oxygen therapy.

Aspergillus and candida are the commonly reported fungi with COVID-19 infection. ${ }^{25}$ In our series, mixed fungal infection was observed on histopathology in 3 of the 37 patients.

Presentation of $58 \%$ cases beyond stage 2 ROCM, indicates the need for a high index of suspicion in COVID patients, especially with concurrent diabetes or immunocompromised status. The limitation of the study was the small sample size.

To conclude, the mutant COVID-19 variant in presence of glycaemic dysregulation predisposes to the development 
of ROCM. Introduction of red flag signs of ROCM in the national guidelines for COVID management shall facilitate early diagnosis which is crucial for combating the mucor related morbidity and mortality.

\section{Abbreviations}

CA-ROCM, COVID-19 associated mucormycosis; HbA1c, Glycosylated haemoglobin.

\section{Disclosure}

The authors declare that they have no known competing financial interests or personal relationships that could have appeared to influence the work reported in this paper.

\section{References}

1. Menon S. India covid: how bad is the second wave? BBC News; May 7, 2021. Available from: https://www.bbc.com/news/56987209/. Accessed July 24, 2021.

2. Sen M. Black fungus: these two states account for nearly $42 \%$ of India's 28,252 mucormycosis cases. Mint; June 7, 2021. Available from: https://www.livemint.com/news/india/black-fungus-28-statessee-28-252-mucormycosis-cases-maharashtra-gujarat-among-worst-hit -states-11623069135171.html. Accessed July 24, 2021.

3. Indian SARS-CoV-2 Genomics Consortium. Available from: https:// dbtindia.gov.in/sites/default/files/Final\%20MoHFW_Mutations\%20in \%20SARS-CoV2_NCDC_Final.pdf. Accessed 24 July, 2021.

4. Singh AK, Singh R, Joshi SR, Misra A. Mucormycosis in COVID-19: a systematic review of cases reported worldwide and in India. Diabetes Metab Syndr. 2021;15(4):102146. doi:10.1016/j. dsx.2021.05.019

5. Pakdel F, Ahmadikia K, Salehi M, et al. Mucormycosis in patients with COVID-19: a cross-sectional descriptive multicentre study from Iran. Mycoses. 2021. doi:10.1111/myc.13334

6. Sen M, Honavar SG, Bansal R, et al. Epidemiology, clinical profile, management, and outcome of COVID-19-associated rhino-orbitalcerebral mucormycosis in 2826 patients in India - collaborative OPAI-IJO Study on Mucormycosis in COVID-19 (COSMIC), report 1. Indian $J$ Ophthalmol. 2021;69(7):1670-1692. doi:10.4103/ijo. IJO 156521

7. Ramaswami A, Sahu AK, Kumar A, et al. COVID-19 associated mucormycosis presenting to the emergency department - an Observational Study of 70 patients. QJM. 2021. doi:10.1093/qjmed/ hcab190

8. Honavar SG. Code mucor: guidelines for the diagnosis, staging and management of rhino-orbito-cerebral mucormycosis in the setting of COVID-19. Indian $J$ Ophthalmol. 2021;69(6):1361-1365. doi:10.4103/ijo.IJO_1165_21

9. Nalbandian A, Sehgal K, Gupta A, et al. Post-acute COVID-19 syndrome. Nat Med. 2021;27(4):601-615. doi:10.1038/s41591-02101283-z
10. Clinical management protocol for COVID-19 in adults. Available from: ht t p s : / / w w w. mo hfw.gov.i n / p d f/ UpdatedDetailedClinicalManagementProtocolforCOVID19adultsdate d24052021.pdf. Accessed July 24, 2021.

11. Petrikkos G, Skiada A, Lortholary O, Roilides E, Walsh TJ, Kontoyiannis DP. Epidemiology and clinical manifestations of mucormycosis. Clin Infect Dis. 2012;54(Suppl 1):S23-S34. doi:10.1093/cid/cir866

12. Peterson KL, Wang M, Canalis RF, Abemayor E. Rhinocerebral mucormycosis: evolution of the disease and treatment options. Laryngoscope. 1997;107(7):855-862. doi:10.1097/00005537199707000-00004

13. Sen M, Lahane S, Lahane TP, Parekh R, Honavar SG. Mucor in a viral land: a tale of two pathogens. Indian J Ophthalmol. 2021;69 (2):244-252. doi:10.4103/ijo.IJO_3774_20

14. Ismaiel WF, Abdelazim MH, Eldsoky I, et al. The impact of COVID-19 outbreak on the incidence of acute invasive fungal rhinosinusitis. Am J Otolaryngol. 2021;42(6):103080. doi:10.1016/j. amjoto.2021.103080

15. Hoenigl M, Seidel D, Carvalho A, et al. The emergence of COVID-19 associated mucormycosis: analysis of cases from 18 countries. SSRN. 2021. doi:10.2139/ssrn.3844587

16. Roden MM, Zaoutis TE, Buchanan WL, et al. Epidemiology and outcome of zygomycosis: a review of 929 reported cases. Clin Infect Dis. 2005;41(5):634-653. doi:10.1086/432579

17. Ravani SA, Agrawal GA, Leuva PA, Modi PH, Amin KD. Rise of the phoenix: mucormycosis in COVID-19 times. Indian J Ophthalmol. 2021;69(6):1563-1568. doi:10.4103/ijo.IJO_310_21

18. Pal R, Bhadada SK, Misra A. Resurgence of COVID-19 and diabetes in India. Diabetes Metab Syndr. 2021;15(3):1037-1038. doi:10.1016/ j.dsx.2021.04.024

19. Lionakis MS, Kontoyiannis DP. Glucocorticoids and invasive fungal infections. Lancet. 2003;362(9398):1828-1838. doi:10.1016/S01406736(03)14904-5

20. Revannavar SM, P s S, Samaga L, V k V. COVID-19 triggering mucormycosis in a susceptible patient: a new phenomenon in the developing world? BMJ Case Rep. 2021;14(4):e241663. doi:10.1136/ bcr-2021-241663

21. Bhuyan A. Experts criticise India's complacency over COVID-19. Lancet. 2021;397(10285):1611-1612. doi:10.1016/S0140-6736(21) 00993-4

22. Gokulshankar S, Mohanty BK. COVID-19 and black fungus. Asian $J$ Med Health Sci. 2021;4(1):138.

23. Brewster CT, Choong J, Thomas C, Wilson D, Moiemen N. Steam inhalation and paediatric burns during the COVID-19 pandemic. Lancet. 2020;395(10238):1690. doi:10.1016/S0140-6736(20)31144-2

24. Selarka L, Sharma S, Saini D, et al. Mucormycosis and COVID-19: an epidemic within a pandemic in India. Mycoses. 2021. doi:10.1111/ myc. 13353

25. Song G, Liang G, Liu W. Fungal co-infections associated with global COVID-19 pandemic: a clinical and diagnostic perspective from China. Mycopathologia. 2020;185(4):599-606. doi:10.1007/s11046020-00462-9 


\section{Publish your work in this journal}

Clinical Ophthalmology is an international, peer-reviewed journal covering all subspecialties within ophthalmology. Key topics include: Optometry; Visual science; Pharmacology and drug therapy in eye diseases; Basic Sciences; Primary and Secondary eye care; Patient Safety and Quality of Care Improvements. This journal is indexed on PubMed
Central and CAS, and is the official journal of The Society of Clinical Ophthalmology (SCO). The manuscript management system is completely online and includes a very quick and fair peer-review system, which is all easy to use. Visit http://www.dovepress.com testimonials.php to read real quotes from published authors. 